\title{
Evaluation of the Microbiological Quality of Conventional and Organic Leafy Greens at the Time of Purchase from Retail Markets in Alexandria, Egypt
}

\author{
ROWAIDA KHALIL ${ }^{1, *}$ and MOHAMED GOMAA ${ }^{2}$ \\ ${ }^{1}$ Department of Botany and Microbiology, Faculty of Science, Alexandria University, Alexandria, Egypt \\ ${ }^{2}$ Department of Food Science, Faculty of Agriculture, Saba Basha, Alexandria University, Egypt
}

Submitted 5 October 2013, revised 19 November 2013, accepted 15 April 2014

Abstract

This is a pioneer study in Egypt that provides some assessment of the microbiological quality of conventional and organic leafy green vegetables that constitute an essential component of the Egyptians' daily diet. A total of 380 samples of unpackaged whole conventional and 84 packaged whole organic leafy greens were collected from retail markets in Alexandria, and analyzed for total aerobic mesophilic count (AMC) and total E. coli count (ECC) using the standard spread plate method. Mean AMC values for organic samples were statistically less $(\mathrm{p}<0.05)$ than those of the corresponding conventional samples. Conventional radish and organic parsley samples had the highest AMC of 7.17 and $7.68 \log$ CFU/g respectively, while conventional green cabbage and organic basil had the lowest AMC of 3.63 and $3.23 \log$ CFU/g respectively. The presence of $E$. coli in $100 \%$ of the studied leafy greens was indicative of potential fecal contamination, in view of open and unhygienic environmental and unsanitary handling conditions, as leafy green items are available for sale by street-vendors. Unsatisfactory AMC and ECC levels encountered in the studied samples, warrant future investigations to determine the potential prevalence of foodborne pathogens, and to identify sources of dominating microorganisms, which could make a contribution to the field of food safety.

Key words: Aerobic counts, E. coli, leafy green vegetables, microbiological quality, organic produce

\section{Introduction}

Consumption of leafy greens (a popular and an indispensable component of the daily menus of Egyptians' diet) have recently increased because of the demand for nutritious foods that ensures sufficient intake of vitamins, minerals, fibers and phenolic compounds with antioxidant and antimicrobial properties (Olaimat and Holley, 2012; Sharma and Kumar, 2013). Derived from the eastern kitchen, leafy greens are routinely consumed as salads, appetizers, spices, or even just as a garnish, and often eaten raw without any heat treatment (Tamberar et al., 2006). Leafy green category of fresh produce are considered as secondary crops in Egypt, and often cultivated in relatively limited areas, and in many cases along irrigation canals and in unused spaces (Ministry of Agriculture and Land Reclamation, 2011). In spite of their nutritional values, conventional leafy greens are generally exposed to microbial contamination through many points in the production system (Rajvanshi, 2010). Consequently, there is a corresponding likelihood that consumers are prone to infections by enteric pathogens (Itohan et al., 2011). Hot climate and environmental conditions (such as dusty streets crowded by vehicles) in Egypt favor bacterial growth in leafy greens sold either by street vendors or at retail local markets.

Organic foods is a small but a growing part of the food industry in Egypt, and its existence provides an element of consumer choice being safer (Adl etal., 2011) and respectful to the environment (Falguera et al., 2012). There is a concern that they may contain higher levels of pathogenic bacteria than conventional produce, due to increased use of manure rather than chemical fertilizers (Loncarevic et al., 2005). However, there is little scientific evidence to support this concern.

The presence of E.coli (normally not pathogenic to humans) in fresh produce not only reflects fecal contamination (Ilic et al., 2008; Ibrahim et al., 2009), but also indicates a possibility that other potential pathogens associated with fecal contamination could be ingested and capable of causing infections (Chang et al., 2013). Foodborne illnesses are not considered serious health threats in Arab countries and typically go

\footnotetext{
* Corresponding author: R. Khalil, Department of Botany and Microbiology, Faculty of Science, Alexandria University, Alexandria, Egypt; phone: +2-01008194996; fax: +2-03-3911794; e-mail: rowaida_georgia@hotmail.com
} 
unreported (FAO/WHO, 2005). To our knowledge, information on safety standards and fecal contamination levels of the extensively consumed leafy greens whether conventional or organic at the time of purchase is underreported, due to lack of surveillance systems, and rigorous enforcement of legislations that would help to minimize or prevent consequent illnesses. On the other hand, total phenolic compounds possess antimicrobial properties, so they might possibly impact the composition and/or load of the contaminating microorganisms in an unexpected way (PuupponenPimiä et al., 2001). Additionally, significant correlation between total phenolic content and the behavior of pathogens and/or the microbial population loads are yet insufficient (Khalil and Frank, 2010), which calls for intensive studies to be conducted on the phenolic constituents in both categories of leafy greens.

The main objective of this research was to fill some of these gaps and obtain baseline information on the general microbiological quality of conventional and organic leafy greens. Levels of total aerobic bacteria and indicator bacteria "E. coli" in organically and conventionally grown leafy greens were determined. The total phenolic content (TPC) was also investigated not only as a parameter of quality (Wu et al., 2004), but to determine the potential antimicrobial effects the leafy green samples extracts might exhibit on the microbial population loads detected at the time of sampling. Such knowledge may be useful to interpret the variation in total microbial counts among the studied leafy green items at the time they are available for consumer purchase. The present work provides valuable scientific data on the general sanitary quality of leafy greens in Egypt; an effort that may aid to reduce microbial spoilage and contaminating pathogens that may pose serious health risk problems to produce consumers.

\section{Experimental}

\section{Materials and Methods}

Sample collection. A total of 380 samples of unpackaged whole conventional and 84 packaged organic leafy greens were purchased from local street vendors, mobile carts, local markets and named super stores in the city of Alexandria in the period April 2011 through April 2012. The studied conventional samples included: Arugula (Eruca sativa), Basil (Ocimum basilicum), Celery (Apium graveolens), Chives (Allium schoenoprasum), Cilantro (Coriander sativum), Dill (Anethum graveolens), Leek (Allium ampeloprasum), Mint (Mentha piperita), Parsley (Petroselinum sativum), Radish (Raphanus sativus) and Spinach (Spinacia oleracea); bundled as bunches (with a rubber band), green and red cabbage (Brassica oleracea var. oleracea), and crisphead lettuce (Lactuca sativa var. capitata). These samples are usually displayed in a loose unwrapped form, till they are packed by vendors in polyethylene plastic bags at the time of consumer purchase. Brand named organic leafy green items from two nation-wide produce companies (except for Radish and Spinach) always packaged either in foam trays and wrapped with plastic ClingWrap or in polyethylene plastic bags were collected in triplicates from large supermarkets and superstores from at least 2 different locations in Alexandria.

Five water and soil samples were directly collected from agricultural fields (at Abees area, south east of Alexandria governorate) that were cultivated with conventional leafy green vegetables. These fields routinely supply several wholesale outlets in Alexandria, from which produce items are distributed to individual local retail markets. It is worth mentioning that we were unable to obtain counterpart environmental samples from organic fields due to difficulties encountered with issuing legitimate sampling permissions from the two organic suppliers. All samples were collected aseptically with ethanol sprayed gloves (to maintain the state in which they were available for consumer purchase) in sterilized polyethylene plastic bags ( $250 \mathrm{~g}$ ), or appropriate sterile plastic containers (for environmental samples), stored at refrigeration temperature $\left(4-6^{\circ} \mathrm{C}\right)$ in an icebox with ice packs, and immediately transported to the laboratory for analysis.

Microbiological analysis of leafy green samples. Leafy green samples were prepared according to the method of Khalil and Frank (2010), weighed, and blended for $30 \mathrm{sec}$ in an 8 -oz. $(237 \mathrm{ml})$ blender jar (Braun, Germany). Each blended sample was filtered with a $50 \mathrm{oz}$. (1.5 lit) sterile filter bag $(15 \times 23 \mathrm{~cm}$, Whirl-Pak, Nasco, Fort Atkinson, WI), and serially diluted with $0.1 \%(\mathrm{w} / \mathrm{v})$ sterile peptone water. Mean AMC and ECC were estimated by the standard spreadplate method by using Tryptic soy agar (TSA; Difco, Becton Dickinson) and Sorbitol MacConkey agar (SMAC; Oxoid, Cambridge, UK) respectively. Plates were incubated at 25 and $37^{\circ} \mathrm{C}$ respectively for $18 \mathrm{~h}$, and microbial counts were expressed as $\log _{10}$ colony forming units (CFU) per gram sample of each leaf type.

Microbiological analysis of agricultural field samples. The five environmental samples mentioned above were analyzed for the presence of indicator bacteria (E. coli) as described by Ibekwe et al. (2011). $1 \mathrm{ml}$ or $1 \mathrm{~g}$ of water or soil samples respectively were aseptically transferred to $9 \mathrm{ml}$ of sterile phosphate-buffered saline ( $\mathrm{pH}$ 7.2) test tubes, vortexed briefly, serially diluted, plated as $100 \mu \mathrm{l}$ aliquots on SMAC plates, and incubated at $37^{\circ} \mathrm{C}$ for $18 \mathrm{~h}$. Counts were expressed as $\log _{10} \mathrm{CFU} / \mathrm{ml}$ or $\mathrm{CFU} / \mathrm{g}$. 
Extraction and analysis of phenolic compounds. Total phenolic (TP) compounds in all leafy green samples were determined as described by Khalil and Frank (2010). Analyses were done in triplicate, and the amount of TP compounds was expressed as mean milligram(s) of gallic acid equivalents (GAE) per gram of fresh weight $(\mathrm{FW}) \pm$ standard deviation (SD) according to the following formula (Francisco and Resurreccion, 2009):

$$
\begin{aligned}
\operatorname{GAE}\left(\frac{\mathrm{mg}}{\mathrm{g} \text { of FW }}\right) & =\frac{\left(A_{760}-b\right)}{m} \\
& \times \frac{\text { yield of extracted dry matter }(\mathrm{mg})}{\mathrm{FW} \text { of leaves }(\mathrm{g})} \\
& \times \frac{1 \mathrm{mg}}{1,000 \mu \mathrm{g}}
\end{aligned}
$$

where $A$ is the absorbance at $760 \mathrm{~nm}, b$ is the y-intercept of the standard curve, and $m$ is slope of standard curve.

Statistical analysis. Data were analyzed with SAS software, version 9.1 (SAS Institute, Inc., Cary, NC) with log-transformed data. Analyses of variance were performed using the ANOVA procedure. Significant $(p<0.05)$ differences between the means of triplicate measurements in each independent trial were determined with Duncan's multiple range test.

\section{Results and Discussion}

Microbiological analysis of conventionally grown leafy greens. Total mean populations of aerobic mesophilic bacteria and E.coli (Table I) indicated that all conventional leafy green samples contained a large bacterial load. The maximum mean AMC was obtained from radish $(7.17 \pm 2.8 \log \mathrm{CFU} / \mathrm{g})$ followed by basil and mint ( $6.88 \pm 0.23$ and $6.77 \pm 0.53 \log$ CFU/g respectively). Lettuce and green cabbage had the lowest mean AMC of $3.15 \pm 0.46$ and $3.63 \pm 1.3 \log \mathrm{CFU} / \mathrm{g}$ respectively. The wide range of AMC for conventional samples (3.63 to $7.17 \log \mathrm{CFU} / \mathrm{g}$ ) was in accordance with the range (3.30 to $8.64 \log \mathrm{CFU} / \mathrm{g}$ ) proposed by Fang et al., (2003). Saddik et al. (1985) and Lund (1993) reported $6.69 \log \mathrm{CFU} / \mathrm{g}$ as the upper limit of AMC for salad vegetable samples, which was lower than the corresponding limit for the studied conventional samples. Furthermore, Koseki and Itoh (2001) specified $<10^{5} \mathrm{CFU} / \mathrm{g}$ as the independent industry standard of AMC for freshcut vegetables during distribution. We speculate that frequency, method of harvest and close proximity of these conventional green leaf types to the soil (affirmed by visible contamination of leaves with soil particles at the time of sampling), in addition to being sold as loose unwrapped bunches may have significantly influenced their initial AMC levels (Machado et al., 2006).
Table I

Mean \pm SD (standard deviation) of aerobic mesophilic counts (AMC) and E. coli counts (ECC) in samples* of whole conventional leafy greens collected at retail local markets in Alexandria. Mean values followed by different superscript letters (a-d) within the same column are significantly $(\mathrm{p}<0.05)$ different. Mean values followed by different superscript letters $(x-y)$ within the same row are significantly $(\mathrm{p}<0.05)$ different.

\begin{tabular}{|l|l|l|}
\hline \multirow{2}{*}{ Leafy green type } & \multicolumn{2}{|c|}{ Log CFU/g } \\
\cline { 2 - 3 } & AMC & ECC \\
\hline Arugula & $5.54^{\mathrm{b}, \mathrm{x}} \pm 0.47$ & $5.06^{\mathrm{c}, \mathrm{x}} \pm 0.99$ \\
\hline Basil & $6.88^{\mathrm{c}, \mathrm{x}} \pm 0.23$ & $4.86^{\mathrm{c}, \mathrm{y}} \pm 0.07$ \\
\hline Cabbage (green) & $3.63^{\mathrm{a}, \mathrm{x}} \pm 1.3$ & $3.77^{\mathrm{b}, \mathrm{x}} \pm 1.17$ \\
\hline Cabbage (red) & $4.89^{\mathrm{b}, \mathrm{x}} \pm 1.9$ & $3.06^{\mathrm{a}, \mathrm{y}} \pm 0.12$ \\
\hline Celery & $5.02^{\mathrm{b}, \mathrm{x}} \pm 1.06$ & $4.3^{\mathrm{c}, \mathrm{y}} \pm 1.07$ \\
\hline Chives & $5.5^{\mathrm{b}, \mathrm{x}} \pm 1.4$ & $4.73^{\mathrm{c}, \mathrm{y}} \pm 0.93$ \\
\hline Cilantro & $5.01^{\mathrm{b}, \mathrm{x}} \pm 0.75$ & $4.89^{\mathrm{c}, \mathrm{x}} \pm 0.97$ \\
\hline Dill & $5.51^{\mathrm{b}, \mathrm{x}} \pm 0.68$ & $4.16^{\mathrm{c}, \mathrm{y}} \pm 1.12$ \\
\hline Leek & $4.94^{\mathrm{b}, \mathrm{x}} \pm 0.9$ & $4.75^{\mathrm{c}, \mathrm{y}} \pm 0.85$ \\
\hline Lettuce & $3.15^{\mathrm{a}, \mathrm{x}} \pm 0.46$ & $3.98^{\mathrm{b}, \mathrm{y}} \pm 0.74$ \\
\hline Mint & $6.77^{\mathrm{c}, \mathrm{x}} \pm 0.53$ & $3.73^{\mathrm{b}, \mathrm{y}} \pm 0.41$ \\
\hline Parsley & $4.91^{\mathrm{b}, \mathrm{x}} \pm 0.57$ & $5.19^{\mathrm{c}, \mathrm{y}} \pm 1.23$ \\
\hline Radish & $7.17^{\mathrm{c}, \mathrm{x}} \pm 2.8$ & $3.91^{\mathrm{b}, \mathrm{y}} \pm 0.97$ \\
\hline Spinach & $5.28^{\mathrm{b}, \mathrm{x}} \pm 1.12$ & $5.97^{\mathrm{d}, \mathrm{y}} \pm 0.89$ \\
\hline
\end{tabular}

${ }^{*}$ Each sample of each leafy green type consists of at least three subsample replicates collected from three different locations (center, east, and west) in Alexandria

Other factors such as store-to-store differences, age of produce at the time of sampling, variations in storage conditions, and handling of vendors (Beuchat and Ryu, 1997) should be taken into account. A study done by Mensah et al. (2002) linked the microbiological variation of samples among local market and street vendors to the use of unsafe water for sprinkling vegetables to keep them fresh; an unhygienic practice that was generally noticeable during sample collection especially by produce vendors using mobile street carts.

Generally speaking, AMC levels of the majority of tested conventional leafy greens exceeded the reference standards proposed in the guidelines of PHLS for leafy salad vegetables sampled at the point of sale (PHLS, 2000). Around $64.3 \%(9 / 14)$ of the conventional leaf types (Table I) were considered unsatisfactory, while $21.4 \%(3 / 14)$ were acceptable (an index reflecting a borderline limit of microbiological quality). Further sampling and inspection of sale premises by environmental health officers may be necessary to determine whether hygiene practices for handling throughout the sale are adequate or not (Gilbert et al., 2000).

Isolates on all SMAC agar plates that were sorbitol positive (red/pink colonies with purple center) or sorbitol negative (translucent colonies or pale brownish colonies), were enumerated as E.coli or presumptive 
pathogenic E.coli respectively (Ibekwe et al., 2011). Further identification of isolates was carried out according to the method of Itohan et al. (2011). E. coli contamination was highest in conventional spinach $(5.97 \pm 0.89 \log \mathrm{CFU} / \mathrm{g})$, and lowest in conventional red cabbage $(3.06 \pm 0.12 \log \mathrm{CFU} / \mathrm{g})$. Analysis of conventional basil and dill samples resulted in mean levels of ECC $(4.86 \pm 0.07$ and $4.16 \pm 1.12 \log$ CFU/g respectively) that were less than their corresponding AMC levels by approximately $1.5-2.0 \log$ units. On the contrary, mean ECC levels in conventional green cabbage, lettuce, parsley, spinach samples exceeded their corresponding AMC levels by 0.14, 0.83, 0.28, $0.69 \mathrm{log}$ units respectively. It is evident that all tested conventional samples were of unacceptable quality from the perspective of their mean ECC levels which exceeded log 2.3 CFU/g (Russel et al., 2010). It has not been possible to conclusively determine if the significant variability in mean ECC values among conventional samples was necessarily related to the background aerobic flora, or to the presence of pathogens (Thunberg et al., 2002).

Microbiological analysis of organically grown leafy greens. Table II presents the levels of AMC and ECC in organically grown leafy greens. The lowest mean AMC was identified from basil samples $(3.23 \pm 0.81 \mathrm{log}$

\section{Table II}

Mean \pm SD (standard deviation) of aerobic mesophilic counts (AMC) and E. coli counts (ECC) in samples* of whole organically grown leafy greens collected at retail super markets in Alexandria. Mean values followed by different superscript letters (a-d) within the same column are significantly $(\mathrm{p}<0.05)$ different. Mean values followed by different superscript letters $(x-y)$ within the same row are significantly $(\mathrm{p}<0.05)$ different.

\begin{tabular}{|l|l|l|}
\hline \multirow{2}{*}{ Leafy green type } & \multicolumn{2}{|c|}{ Log CFU/g } \\
\cline { 2 - 3 } & \multicolumn{1}{|c|}{ AMC } & ECC \\
\hline Arugula & $6.75^{\mathrm{c}, \mathrm{x}} \pm 0.52$ & $2.85^{\mathrm{b}, \mathrm{y}} \pm 0.12$ \\
\hline Basil & $3.23^{\mathrm{a}, \mathrm{x}} \pm 0.81$ & $2.75^{\mathrm{b}, \mathrm{y}} \pm 0.73$ \\
\hline Cabbage (green) & $3.62^{\mathrm{a}, \mathrm{x}} \pm 0.08$ & $2.11^{\mathrm{b}, \mathrm{y}} \pm 0.18$ \\
\hline Cabbage (red) & $5.0^{\mathrm{b}, \mathrm{x}} \pm 0.03$ & $3.02^{\mathrm{b}, \mathrm{y}} \pm 0.61$ \\
\hline Celery & $4.47^{\mathrm{b}, \mathrm{x}} \pm 0.68$ & $2.02^{\mathrm{b}, \mathrm{y}} \pm 0.23$ \\
\hline Chives & $5.16^{\mathrm{b}, \mathrm{x}} \pm 0.75$ & $3.39^{\mathrm{c}, \mathrm{y}} \pm 0.83$ \\
\hline Cilantro & $3.5^{\mathrm{a}, \mathrm{x}} \pm 0.91$ & $4.35^{\mathrm{c}, \mathrm{y}} \pm 0.29$ \\
\hline Dill & $3.8^{\mathrm{a}, \mathrm{x}} \pm 0.92$ & $<0.9^{\mathrm{a}, \mathrm{y}} \pm 0.78$ \\
\hline Leek & $6.26^{\mathrm{c}, \mathrm{x}} \pm 0.55$ & $6.0^{\mathrm{d}, \mathrm{y}} \pm 0.34$ \\
\hline Lettuce & $4.81^{\mathrm{b}, \mathrm{x}} \pm 0.34$ & $4.42^{\mathrm{c}, \mathrm{y}} \pm 0.65$ \\
\hline Mint & $6.05^{\mathrm{c}, \mathrm{x}} \pm 0.47$ & $2.9^{\mathrm{b}, \mathrm{y}} \pm 0.57$ \\
\hline Parsley & $7.68^{\mathrm{d}, \mathrm{x}} \pm 0.66$ & $3.81^{\mathrm{c}, \mathrm{y}} \pm 0.86$ \\
\hline Radish & $\mathrm{NA}$ & $\mathrm{NA}$ \\
\hline Spinach & $\mathrm{NA}$ & $\mathrm{NA}$ \\
\hline
\end{tabular}

* Each sample of each leafy green type consists of at least three subsample replicates collected from at least two different supermarkets and superstores in Alexandria

$\mathrm{NA}=$ not available
CFU/g), which was almost half the AMC levels recovered from conventional basil samples $(6.88 \pm 0.23 \mathrm{log}$ $\mathrm{CFU} / \mathrm{g})$. Organic and conventional green cabbage had almost the same mean AMC $(3.62 \pm 0.08$ and $3.63 \pm 1.3 \log \mathrm{CFU} / \mathrm{g}$ respectively). A similar observation was found in organic and conventional red cabbage samples, where their mean AMC levels were not statistically different $(\mathrm{p}>0.05)$. Organic arugula and parsley samples were considered the most unacceptable and potentially hazardous samples $\left(10^{7}-10^{8} \mathrm{CFU} / \mathrm{g}\right)$, which points out to the importance of locating the source of problem, and that a detailed risk assessment is recommended (Gilbert etal., 2000). Our data showed that more organically grown leafy green types $(4 / 14 ; 33.3 \%)$ in comparison to the conventional types, were rated as good (Aycicek et al., 2006), which confirms the advantage of packaging process and reduced influence of handling during packaging and storage (Lester, 2006). However, we found that 5 (arugula, red cabbage, leek, lettuce and parsley) out of 12 tested organic samples demonstrated higher values of mean AMC compared to those of the corresponding conventional samples, which coincides with the results of Mukherjee et al. (2004). Unavailability of defined sections dedicated solely for organic products sale at organic superstores may enhance cross contamination with conventional produce items. E. coli loads showed a wide variation in organic leafy green samples ranging from $2.02 \mathrm{log}$ $\mathrm{CFU} / \mathrm{g}$ (in celery) to $6.0 \mathrm{log} \mathrm{CFU} / \mathrm{g}$ (in leek). In general, all organic samples were significantly $(p<0.05)$ less contaminated with E.coli than the corresponding conventional ones except for organic leek and lettuce. These results provide evidence that the overall microbial quality of the tested organic produce items were higher than the corresponding conventional items (Bourne and Prescott, 2002). However, this is not a comparative study of organic vs. conventional produce. Such investigations would require detailed microbiological risk assessment coupled with clear determination of the exact source of contaminating microorganisms.

Microbiological analysis of samples from agricultural fields. At the pre-harvest stage, fresh produce are more likely to be contaminated through irrigation water containing untreated sewage and improperly composted manure (FDA, 2012). Therefore, this experiment was carried out to document some hygienic practices of farm irrigation. This may shed some light on the microbiological quality of conventional leafy green samples at the pre-harvest stage, which could lead to subsequent higher microbial burden and/or possible internalization of potential pathogens present on the plant surface (Mdluli et al., 2013) at the time of purchase. Results in table III confirmed that the levels of E. coli contamination in the five indicated 
Table III

Mean \pm SD (standard deviation) of E. coli counts (ECC) in samples collected from agricultural fields at Abees area, south east of Alexandria.

\begin{tabular}{|c|l|c|}
\hline $\begin{array}{c}\text { Sample } \\
\#\end{array}$ & \multicolumn{1}{|c|}{ Sample description } & $\begin{array}{c}\text { ECC (log CFU/ml water } \\
\text { or log CFU/g soil) }\end{array}$ \\
\hline 1 & Water samples from water beds and reservoirs & $5.18 \pm 0.92$ \\
\hline 2 & Drainage water & $4.57 \pm 0.44$ \\
\hline 3 & Irrigation water & $2.56 \pm 0.65$ \\
\hline 4 & Soil samples of agricultural fields cultivated with leafy greens & $3.70 \pm 0.25$ \\
\hline 5 & Soil sediments contaminated with drainage water (collected at the banks of drainage canals) & $4.41 \pm 0.47$ \\
\hline
\end{tabular}

samples were significantly $(\mathrm{p}<0.05)$ different. Drainage water samples contained almost double the load of E. coli $(4.57 \pm 0.44 \log \mathrm{CFU} / \mathrm{ml})$ recovered from irrigation water samples $(2.56 \pm 0.65 \log \mathrm{CFU} / \mathrm{ml})$, which is considered a normal result and a non-health hazard condition only if the former source was not used for irrigation purposes; a practice barely avoided by farmers due to interruption and sometimes cessation of irrigation at the indicated area. Maximum level of ECC $(5.18 \pm 0.92 \log \mathrm{CFU} / \mathrm{g})$ was detected in water samples collected from water beds and reservoirs in the vicinity of the agricultural fields cultivated with leafy greens. Furthermore, we have witnessed a poor hygienic irrigation practice occurring at this sampling site; the use of farmers to water beds (containing visible shed feces of farm animals) in washing the harvested leafy greens before packing them on truck docks to be transported to wholesale outlets in Alexandria. Moreover, farmers acknowledged this water as a source of contamination in the farming environment (personal communication) which contributing to final leafy greens standard of quality. Educating farmers in particular on the risk involved in the use of water bodies subjected to varying degrees of abuses that result in contamination of irrigation water and manure is a matter of prime concern (Cordelia et al., 2003).

Determination of TPC. TPC was investigated to determine whether levels of microbial populations in the tested leafy greens are negatively affected by the antimicrobial compounds in their extracts (Nithiyanantham et al., 2012). Average TPC in ethanolic extracts of conventional and organic leafy greens (Table IV) ranged from 6.95 to 72.18 and from 2.88 to $109.87 \mathrm{mg}$ of GAE/g FW respectively. Overall, TP data provides convincing evidence that agricultural methods utilizing no or very little pesticides, may have contributed to the significantly $(\mathrm{p}<0.05)$ higher mean TP levels detected in extracts of organically grown products compared to those detected in the corresponding extracts of conventional samples. For instance, TPC in extracts of organic mint samples $(72.02 \pm 0.79 \mathrm{mg}$ of GAE/g FW) was fourfold that estimated in extracts of conventional mint samples $(17.86 \pm 6.87 \mathrm{mg}$ of GAE/g FW). Low ECC
(3.06 log CFU/g) was recovered from conventional red cabbage leaves, while their ethanolic extracts contained the maximum levels of TP (72.18 mg of GAE/g FW). Conventional spinach leaves showed relatively higher levels of AMC and ECC (5.28 and $5.97 \log$ CFU/g respectively) than those recovered from lettuce leaves (3.15 and 3.98 $\log$ CFU/g respectively), in spite of the higher TP levels detected in their leaf extracts (57.73 mg of GAE/g FW) compared to those detected in lettuce leaves extracts $(6.95 \mathrm{mg}$ of GAE/g FW). This may be attributed to the efficacy of other compounds such as allyl isothiocyanate (AITC), possessing antimicrobial, anticancer and cytoprotective activities (Zhang, 2010). Therefore, we could not confidently draw a meaningful conclusion of a consistent relationship between TP levels in leaf extracts and AMC or

\section{Table IV}

Total phenolic content (TPC) in ethanolic extracts of conventional and organic leafy green samples. The concentration of total phenolics was expressed as the mean milligram(s) of gallic acid equivalents (GAE) per gram of fresh weight $(F W) \pm S D$ (standard deviation). Mean values followed by different superscript letters within the same column are significantly $(\mathrm{p}<0.05)$ different.

\begin{tabular}{|l|l|l|}
\hline \multirow{2}{*}{ Leafy green type } & \multicolumn{2}{|c|}{ TPC (GAE/g of FW) } \\
\cline { 2 - 3 } & Conventional & Organic \\
\hline Arugula & $21.0^{\mathrm{c}} \pm 0.13$ & $41.22^{\mathrm{c}} \pm 0.17$ \\
\hline Basil & $9.0^{\mathrm{a}} \pm 0.62$ & $11.97^{\mathrm{b}} \pm 0.20$ \\
\hline Cabbage (green) & $19.56^{\mathrm{b}} \pm 0.25$ & $42.58^{\mathrm{c}} \pm 0.29$ \\
\hline Cabbage (red) & $72.18^{\mathrm{d}} \pm 0.77$ & $94.7^{\mathrm{e}} \pm 0.44$ \\
\hline Celery & $45.04^{\mathrm{d}} \pm 0.90$ & $55.99^{\mathrm{c}} \pm 0.33$ \\
\hline Chives & $14.88^{\mathrm{b}} \pm 5.11$ & $9.67^{\mathrm{b}} \pm 0.37$ \\
\hline Cilantro & $25.92^{\mathrm{c}} \pm 2.08$ & $57.09^{\mathrm{c}} \pm 0.84$ \\
\hline Dill & $56.14^{\mathrm{d}} \pm 1.5$ & $89.18^{\mathrm{d}} \pm 1.03$ \\
\hline Leek & $30.32^{\mathrm{c}} \pm 2.0$ & $35.0^{\mathrm{c}} \pm 0.83$ \\
\hline Lettuce & $6.95^{\mathrm{a}} \pm 1.65$ & $2.88^{\mathrm{a}} \pm 0.64$ \\
\hline Mint & $17.86^{\mathrm{b}} \pm 6.87$ & $72.02^{\mathrm{d}} \pm 0.79$ \\
\hline Parsley & $50.52^{\mathrm{d}} \pm 2.46$ & $109.87^{\mathrm{e}} \pm 1.88$ \\
\hline Radish & $15.65^{\mathrm{b}} \pm 11.2$ & NA \\
\hline Spinach & $57.73^{\mathrm{d}} \pm 2.3$ & NA \\
\hline
\end{tabular}

NA = not available 
ECC recovered from their corresponding leaves, which necessitates further investigations.

Conclusions. In this study, the AMC was a successful microbiological tool for determining produce safety and quality, and was regarded as an index of existence of favorable conditions for proliferation of microorganisms. Determining ECC exceeding purchase levels $(10 \mathrm{CFU} / \mathrm{g})$, together with the detecting several conventionally grown items with unacceptable quality, constitutes a warning sign to a situation of risk since a percentage of the Egyptian consumers rarely wash fresh produce products before consumption. Results of this study emphasize the need to promote consumer awareness about the possible health hazards arising from poor handling of these vegetables at several points of the supply chain. Regulatory bodies should establish a uniform system to effectively mandate Good Agricultural Practices (GAPs) and ensure that microbiological standards are practiced by farmers and marketers for cultivation, handling and distribution of salad vegetables.

\section{Acknowledgments}

The authors would like to thank Alexandria University (Egypt) Research Enhancement Program (Alex Rep) for financial and technical support. This research was supported by a project funded by Alex Rep (project No. HLTH-10) in the period April 2011-April 2013.

The authors gratefully acknowledge the members of the project team: Eng. Shaimaa Anwar, and the junior scientist Miss Nabila Shabana for their technical support.

\section{Literature}

Abed S.A., H.M. Sirat and T. Muhammad. 2013. Total phenolic, antioxidant, antimicrobial activities and toxicity study of Gynotroches acillaris blume (Phizopheraceae). EXCELI J. 12: 404-412.

Adl S., D. Iron and T. Kolokolnikov. 2011. A threshold area ration of organic to conventional agriculture causes recurrent pathogen outbreaks in organic agriculture. Sci. Total Environ. 409: 2192-2197. Aycicek H., U. Oguz and K. Karci. 2006. Determination of total aerobic and indicator bacteria on some raw eaten vegetables from wholesalers in Ankara, Turkey. Int. J. Hyg. Environ. Health. 209: 197-201.

Beuchat L.R. and J.H. Ryu. 1997. Produce handling and processing practices. Emerg. Infect. Dis. 3: 459-465.

Bourne D. and J. Prescott. 2002. A comparison of the nutritional value, sensory qualities and food safety of organically and conventionally produced foods. Crit. Rev. Food Sci. Nutr. 42: 1-34.

Chang W.S., L. Afsah-Hejri, Y. Rukayadi, A. Khatib, Y.L. Lye, Y.Y. Loo, N. Mohd Shahril, S. Puspanadan, C.H. Kuan, S.G. Goh, Y.H.T. John, Y. Nakaguchi, M. Nishibuchi and R. Son. 2013. Quantification of Escherichia coli O157:H7 in organic vegetables and chickens. Int. Food Res. J. 20: 1023-1029.

Cordelia N.O., J.U. Veronica and M. Galadima. 2003. Occurrence of pathogens on vegetables harvested from soils irrigated with contaminated streams. Sci. Total Environ. 311: 49-56.

Falguera V., N. Aliguer and M. Falguera. 2012. An integrated approach to current trends in food consumption: Moving toward functional and organic products? Food Control. 26: 274-281.
Fang T.J., Q.K. Wei, C.W. Liao, M.J. Hung and T.H. Wang. 2003. Microbiological quality of $18^{\circ} \mathrm{C}$ ready-to-eat food products sold in Taiwan. Int. J. Food Microbiol. 80: 241-250.

Food and Drug Administration (FDA). 2012. Bad Bug Book: Foodborne Pathogenic Microorganisms and Natural Toxins, $2^{\text {nd }}$ ed. p. 75-79.

Food and Agriculture Organization of the United Nations and World Health Organization (FAO/WHO). 2005. Regional meeting on food safety for the Near East, Amman, Jordan. Practical actions to promote food safety. Final report. Available at: ftp://ftp.fao.org/ es/esn/food/meetings/NE_report_en.pdf. Accessed 22 September 2013.

Francisco M.L. and A.V. Resurreccion. 2009. Total phenolics and antioxidant capacity of heat-treated peanut skins. J. Food Compost. Anal. 22: 16-24.

Gilbert R.J., J. de Louvois, T. Donovan, C. Little, K. Nye, C.D. Ribeiro, J. Richards, D. Roberts and F.J. Bolton. 2000. Guidelines for the microbiological quality of some ready-to-eat foods sampled at the point of sale. PHLS Advisory Committee for Food and Dairy Products. Commun. Dis. Pub. Health. 3: 163-167.

Ibekwe A.M., S.E. Murinda and A.K. Graves. 2011. Microbiological evaluation of water quality from urban watersheds for domestic water supply improvement. Int. J. Environ. Res. Pub. Health. 8: 4460-4476.

Ibrahim T.A., B.S. Jude-Ojei, E.O. Giwa and V.T. Adebote. 2009. Microbiological analysis and effect of selected antibacterial agents on microbial load of fluted pumpkin, cabbage and bitter leaves. Res. J. Agric. Biol. Sci. 5: 1143-1145.

Ilic S., J. Odomeru and J.T. LeJeune. 2008. Coliforms and prevalence of Escherichia coli and foodborne pathogens on minimally processed spinach in two packing plants. J. Food Prot. 71: 2398-2403.

Itohan A.M., O. Peters and I. Kolo. 2011. Bacterial contaminants of salad vegetables in Abuja municipal area council, Nigeria. Malays. J. Microbiol. 7: 111-114.

Khalil R. and J. Frank. 2010. Behavior of Escherichia coli O157:H7 on damaged leaves of spinach, lettuce, cilantro, and parsley stored at abusive temperatures. J. Food Prot. 73: 212-220.

Koseki S. and K. Itoh. 2001. Prediction of microbial growth in fresh-cut vegetables treated with acidic electrolyzed water during storage under various temperature conditions. J. Food Prot. 64: 1935-1942.

Lester G.E. 2006. Organic versus conventionally grown produce. Agricultural Research Service, Kika. Hortiscience. 41: 296-300.

Loncarevic S., G.S. Johannessen and L.M. Rorvik. 2005. Bacteriological quality of organically grown leaf lettuce in Norway. Lett. Appl. Microbiol. 41: 186-189.

Lund B.M. 1993. The microbiological safety of prepared salad vegetables. Food Technol. Int. Eur. 1993: 196-200.

Machado D.C., C.M. Maia, I.D. Carvalho, N.F. da Silva, M.C. André and A.B. Serafini. 2006. Microbiological quality of organic vegetables produced in soil treated with different types of manure and mineral fertilizer. Braz. J. Microbiol. 37: 38-544.

Mdluli F., J. Thamaga-Chitja and S. Schmidt. 2013. Appraisal of hygiene indicators and farming practices in the production of leafy vegetables by organic small-scale farmers in uMbumbulu (Rural KwaZulu-Natal, South Africa). Int. J. Environ. Res. Public. Health. 10: 4323-4338.

Mensah P.D., D. Yeboah-Manu, K. Owusu-Darko and A. Ablordey. 2002. Street foods in Accra, Ghana: How safe are they? Bull. WHO. 80: 546-554.

Ministry of Agriculture and Land Reclamation E. 2011. Bulletin of statistics prices, costs and net returns. Cairo, Ministry of Agriculture and Land Reclamation, Egypt 1: 124-136. 
Mukherjee A., D. Speh, E. Dyck and F. Diez-Gonzalez. 2004 Preharvest evaluation of coliforms, Escherichia coli, Salmonella, and Escherichia coli O157:H7 in organic and conventional produce grown by Minnesota farmers. J. Food Prot. 67: 894-900.

Nithiyanantham S., S. Varadharajan and P. Siddhuraju. 2012. Differential effects of processing methods on total phenolic content, antioxidant and antimicrobial activities of three species of Solanum. J. Food Drug Anal. 20: 844-854.

Olaimat A.N. and R.A. Holley. 2012. Factors influencing the microbial safety of fresh produce: A review. Food Microbiol. 32: 1-19.

Public Health Laboratory Service (PHLS). 2000. Guidelines for the microbiological quality of some ready-to-eat foods sampled at the point of sale. Commun. Dis. Pub. Health. 3: 163-167.

Puupponen-Pimiä R., L. Nohynek, C. Meier, M. Kähkönen, M. Heinonen, A. Hopia and K.-M. Oksman-Caldentey. 2001 Antimicrobial properties of phenolic compounds from berries. J. Appl. Microbiol. 90: 494-507.
Rajvanshi A. 2010. Bacterial load on street vended salads in Jaipur city, India. Internet J. Food Safety. 12: 136-139.

Saddik M.F., M.R. El-sherbeeny and F.L. Bryan. 1985. Microbiological profiles of Egyptian raw vegetables and salads. J. Food Prot. 48: 883-886.

Sharma H.P. and R.A. Kumar. 2013. Health security in ethnic communities through nutraceutical leafy vegetables. J. Environ. Res. Dev. 7: 1423-1429.

Thunberg R.L., T.T. Tran, R.W. Bennett, R.N. Matthews and N. Belay. 2002. Microbial evaluation of selected fresh produce obtained at retail markets. J. Food Prot. 65: 677-682.

Wu X., L. Gu, J. Holden, D.B. Haytowitz, S.E. Gebhardt, G. Beecher and R.L. Prior. 2004. Development of a database for total antioxidant capacity in foods: a preliminary study. J. Food Compost. Anal. 17: 407-422.

Zhang Y. 2010. Allyl isothiocyanate as a cancer chemopreventive phytochemical. Mol. Nutr. Food Res. 54: 127-135. 
